\title{
Selected topics from the 32nd International Symposium on Shock Waves, Singapore, July 14-19, 2019
}

\author{
H. Kleine ${ }^{1}$
}

Published online: 18 October 2021

(c) The Author(s), under exclusive licence to Springer-Verlag GmbH Germany, part of Springer Nature 2021

In July 2019, the 32nd International Symposium on Shock Waves (ISSW) was held at the National University of Singapore. This biennial definitive international meeting covers all aspects of high-speed compressible fluid mechanics, that is, analytical, experimental, and numerical studies, both basic and applied, of shock wave- and blast wave-related phenomena. A total of 308 presentations were made during the weeklong meeting, which included nine plenary lectures. More details on the meeting itself can be found in [1].

The participants of the meeting were encouraged to convert their contribution to the conference into an archival journal paper. A total of 23 papers presented at the meeting were submitted to the Shock Waves Journal to be included in the Special ISSW32 Issue. All manuscripts received underwent the usual reviewing procedure for publications in the Shock Waves Journal: They were reviewed by at least two independent referees, each of which an internationally recognized expert in the field, and they were only accepted for publication if a corresponding consensus was reached. The rigor and robustness of this review process are illustrated by the fact that 13 of the submitted manuscripts were rejected, and two others were withdrawn by the authors after the review process had requested major revisions. Eight papers were eventually accepted, most of them requiring at least two revisions.

These eight papers mirror the wide spectrum of topics covered in the Shock Wave Symposium: Schunck et al. and Blanc et al. discuss different aspects of blast wave mitigation; Selcan et al. and Chan et al. introduce new diagnostic and operational technologies for hypersonic shock tunnels; Utkin et al. and Sakamura et al. present investigations on the interaction of shock waves with moving bodies; Shi et al. investigate the process of supercavitation of projectiles exit-

H. Kleine

h.kleine@adfa.edu.au

1 School of Engineering and Information Technology, University of New South Wales Canberra, Northcott Drive, Canberra, ACT 2600, Australia ing a liquid; and Dias and Sharipov investigate the shock wave structure in noble gases.

We would like to thank all authors who submitted their papers, but also the handling editors and the reviewers, who played a major role in ensuring that the standards of archival journal publications were maintained. The COVID-19 pandemic, which started about six months after the symposium, unfortunately affected and delayed the review process in a significant way, so that this issue can only be published about two years after the symposium was held.

\section{Reference}

1. Khoo, B.C., Teo, C.J., Li, J.M.: Report on the 32nd international symposium on shock waves. Shock Waves 30, 559-561 (2020). https://doi.org/10.1007/s00193-020-00955-y

Publisher's Note Springer Nature remains neutral with regard to jurisdictional claims in published maps and institutional affiliations. 